\title{
Are we
}

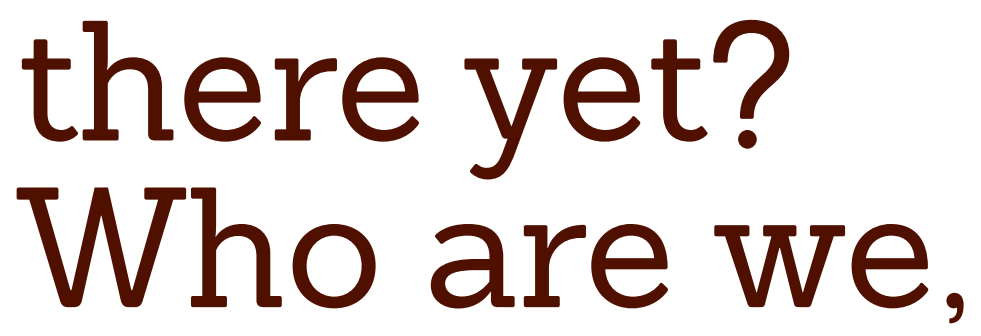

where are

we going?

\section{Bethlehem Mariam}

Keywords

Vancouver, BC

Bethlehem Mariam is an artist and journalist

Black art, diaspora, visual

based in Vancouver, B.C. She received her B.A from Concordia University. Her practice spans painting, drawing, collage and zine-making. She works primarily with watercolors, ink and acrylic paint. She also produces various comedy shows including "Blackity Black Show." You can find her art book with Moniker Press here:

https://www.monikerpress.ca/product/are-we-there-yet/ 


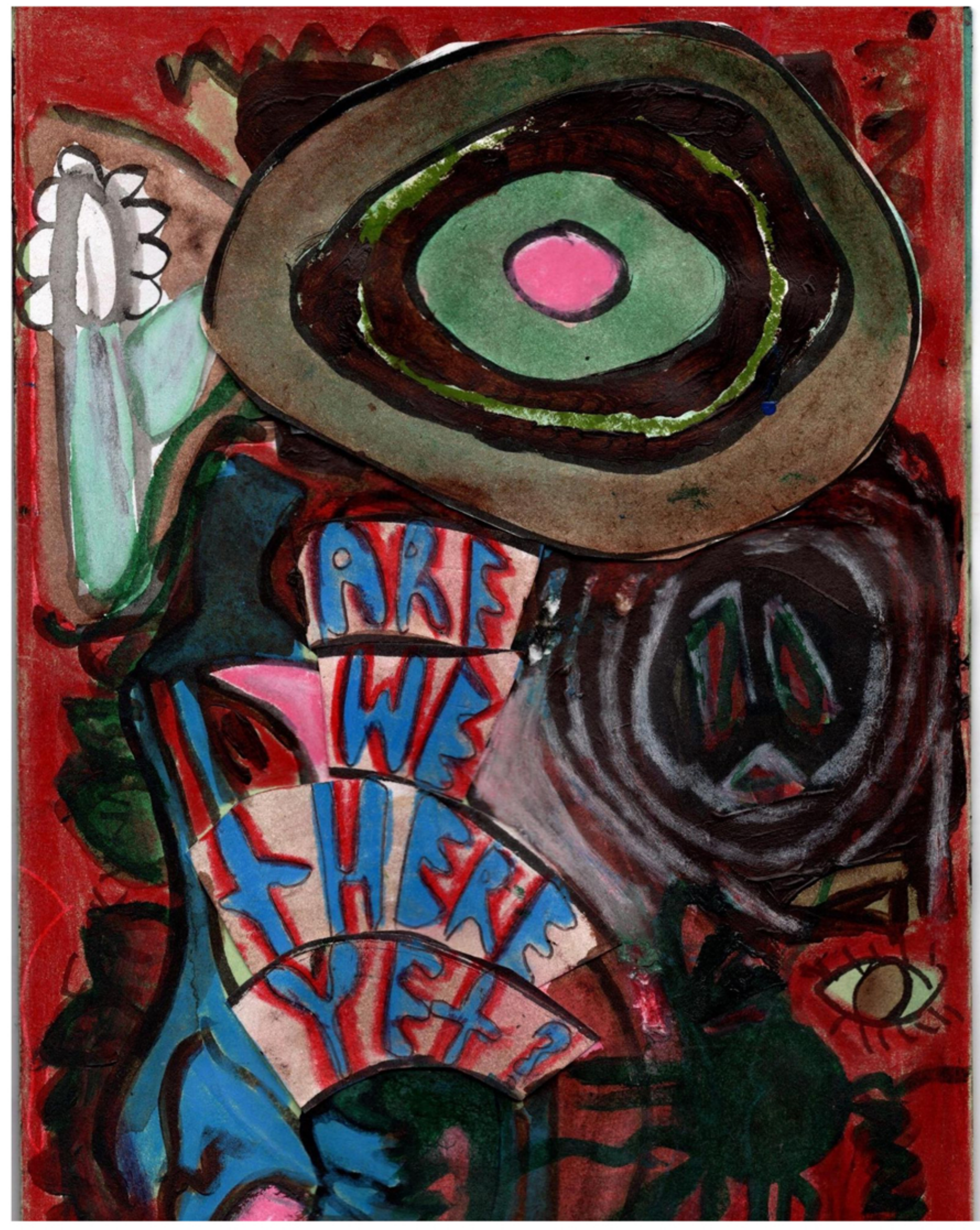




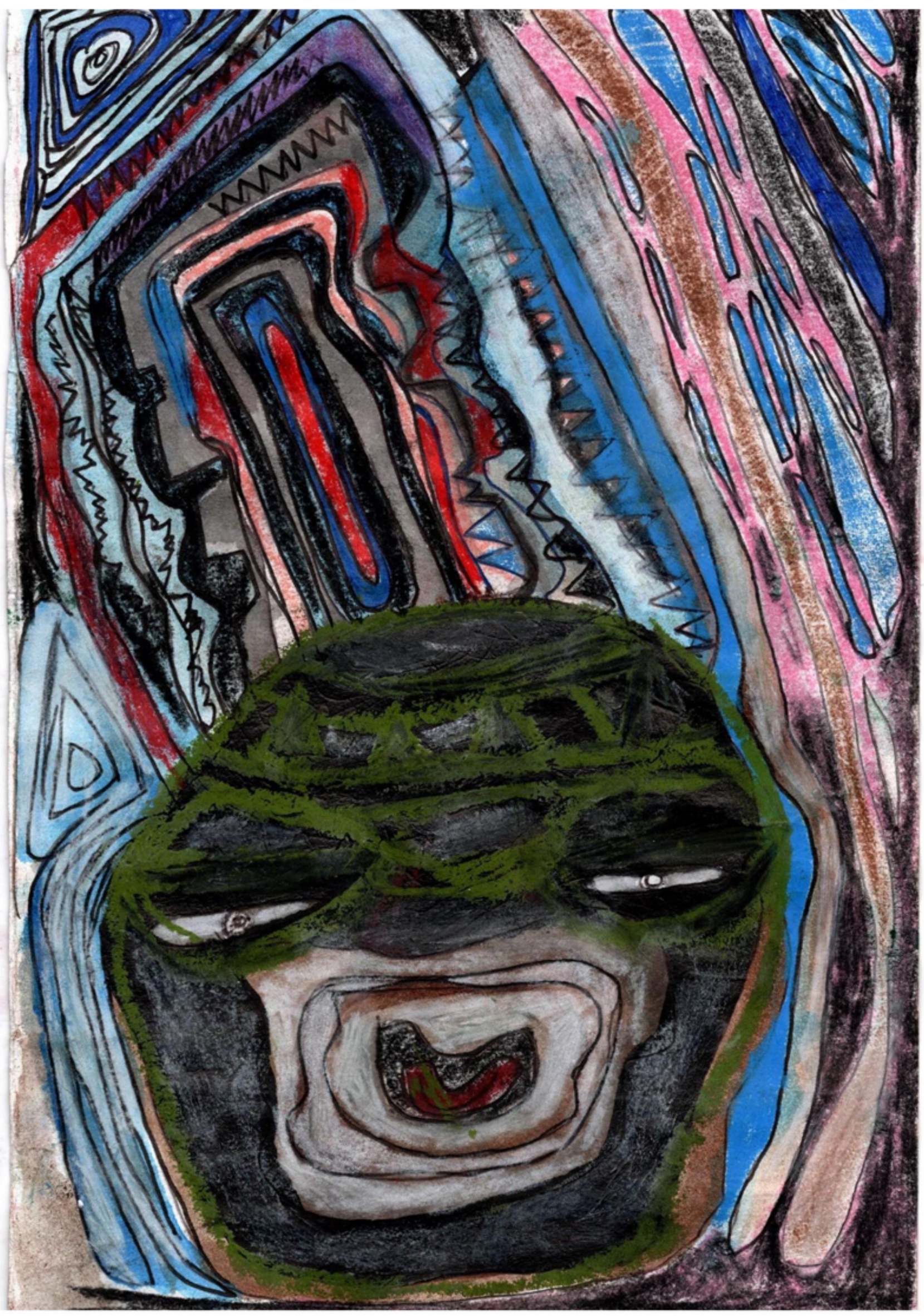




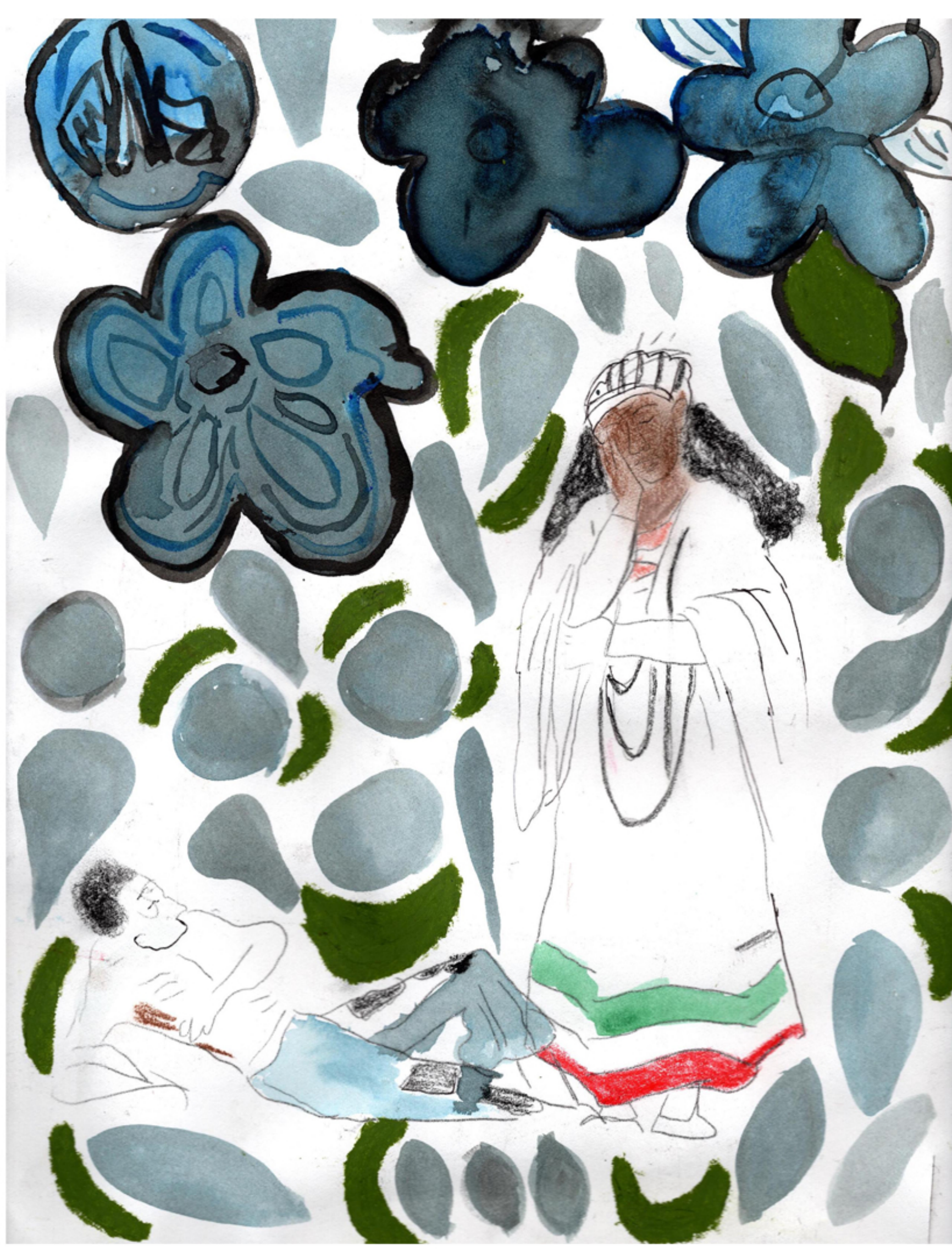




\section{Artist Statement}

This series is inspired by the community resistance work I witnessed amidst a summer of racial reckoning. I was deeply moved by the people who were most prepared for the moment - people who had been doing the work for decades. I learned so much from our Black writers, activists, students, teachers, and artists who had already been engaged in radical politics, mutual aid and other support systems. I witnessed my community and the younger generation mobilizing their peers and showing up on the ground when it mattered the most. I spent that summer thinking, grieving, and dreaming about our freedom. I began asking myself questions that have become the title of this series: Are we there yet? Who are we? Where are we going?

Last summer seems like a lifetime ago. I began working on this series as I was processing the reality that the work is ongoing, the struggle continues, and we're certainly not there yet.

These pieces are rooted in my specific Ethiopian diasporic identity. I've included vibrant red, black, and green colours which is what I'm intuitively drawn to. Thanks to my family's love of African visual art, I grew up seeing the richness of Black faces in art, sculpture, and magazine covers around the house on tables, shelves, walls which has profoundly informed my practice and these pieces in particular. I'm trying to build upon the foundation laid by incredible Black artists that came before me who were ahead of their time. When I think of the future, I think of Black people. Part of my work is imagining how we live in the future. I think imagining worlds and possibilities for us, that are outside systems of domination and control - that's where my work exists, and that's where I as an artist thrive. 